Marquette University

e-Publications@Marquette

College of Nursing Faculty Research and

Publications

Nursing, College of

$3-2001$

\title{
Dietary Intake and Energy Expenditure of Female Collegiate Swimmers During Decreased Training Prior to Competition
}

Laura Ousley-Pahnke

Community Memorial Hospital

David R. Black

Purdue University

Randall J. Gretebeck

Marquette University, randall.gretebeck@marquette.edu

Follow this and additional works at: https://epublications.marquette.edu/nursing_fac

Part of the Nursing Commons

\section{Recommended Citation}

Ousley-Pahnke, Laura; Black, David R.; and Gretebeck, Randall J., "Dietary Intake and Energy Expenditure of Female Collegiate Swimmers During Decreased Training Prior to Competition" (2001). College of Nursing Faculty Research and Publications. 875.

https://epublications.marquette.edu/nursing_fac/875 
Marquette University

e-Publications@Marquette

\section{Nursing Faculty Research and Publications/College of Nursing}

This paper is NOT THE PUBLISHED VERSION.

Access the published version via the link in the citation below.

Journal of the American Dietetic Association, Vol. 101, No. 3 (2001, March): 351-354. DOI. This article is (C) Elsevier and permission has been granted for this version to appear in e-Publications@Marquette. Elsevier does not grant permission for this article to be further copied/distributed or hosted elsewhere without express permission from Elsevier.

\section{Dietary Intake and Energy Expenditure of Female Collegiate Swimmers During Decreased Training Prior to Competition}

\section{Laura Ousley-Pahnke}

Clinical Dietitian at Community Memorial Hospital, Menomonee Falls, WI

David R. Black

Professor of Health Promotion; Health Sciences; Food and Nutrition; and Nursing in the Department of Health, Kinesiology, and Leisure Studies, Purdue University, West Lafayette, IN

Randall J. Gretebeck

Division of Health, Physical Education, and Recreation, College of Education, Wayne State University, Detroit, MI

Swimmers, like all athletes, require a well-balanced diet with adequate energy intake for normal daily activities and the demands of training and competition. Investigators have typically studied nutritional status of athletes during heavy or peak training (1), (2). These studies generally show low levels of energy intake relative to expenditure, and carbohydrate intake also well below recommendations. However, several studies of the effects of exercise on energy intake have shown that as exercise energy expenditure increases or decreases, dietary intake tends to remain the same (3), (4), (5). Because training volume varies with the competitive season, it is important to investigate dietary intake at different levels of training. One period of training during which nutritional intake has not been studied is during taper, a period of decreased training before an athletic event to 
improve mental and physical readiness for competition (6). An important issue during this period is whether the discrepancy between energy intake and expenditure previously reported during heavy training is maintained during a period of reduced training.

Another consideration is the number of reduced-fat food products consumed by female athletes. (In recent years, there has been an overwhelming increase in the availability of low-fat and fat-free food products.) Increased use of these foods may contribute to the increased carbohydrate intake observed in some recent studies of female athletes (7), (8), (9), which contrasts with earlier studies suggesting that carbohydrate intakes of female endurance athletes are $14 \%$ to $24 \%$ lower than recommended (1).

\section{Method}

\section{Subjects}

Sixteen women eumenorrheic collegiate swimmers at a large Midwestern university swim team participated in this study. All data were collected during a taper phase (swimming 4,300 meters/day, 6 days/week) of training before competition. All procedures were explained verbally and in writing, and informed consent was obtained in accordance with the University Human Subjects Review Board.

\section{Dietary Information}

A food record was used to collect dietary intake for 4 consecutive days, including 1 weekend day. Subjects were given a record book along with verbal and written instructions about how to record all food and fluids consumed. During the instruction, food models were used to help identify portion sizes. Records were reviewed at swim practice each day by a Registered Dietitian for thoroughness and specificity. Any clarification needed from the subject was then obtained. The records were analyzed for energy intake and nutrient density using Nutritionist IV (version 4.1, 1997, First DataBank, San Bruno, CA).

\section{Energy Expenditure/Activity}

Vigorous physical activity outside of practice was recorded by each subject. Physical activity during practice was prescribed each day by the swim coach. Exercise varied according to the distance each subject was required to swim, based on the events in which swimmers competed. Each group of swimmers (sprint, middle-distance, or distance) used all 4 competitive strokes: butterfly, backstroke, breast-stroke, and free stroke (crawl). Training consisted of a daily afternoon session lasting $11 / 2$ to $21 / 2$ hours. Tabulated energy costs for the different strokes were used to estimate energy expenditure during training sessions (10). Sedentary energy expenditure (SEE) unrelated to training or vigorous physical activity outside training sessions was calculated using equations developed by Webb et al (11), which includes the energy costs of resting metabolic rate, sleeping metabolic rate, the thermogenic effect of food, and light activity. Total energy expenditure for the 4 days was estimated by adding the energy costs of swimming and other vigorous physical activity and SEE.

\section{Results and Discussion}

The mean [ \pm standard deviation (SD)] age was $19.6 \pm 1.2$ years, height was $173.0 \pm 5.1 \mathrm{~cm}$, weight was $66.2 \pm 5.4 \mathrm{~kg}$, and $\mathrm{BMI}$ was $22.1 \pm 1.3$.

Table 1 presents descriptive statistics about average daily energy intake, including the distribution of carbohydrate, protein, and fat consumption. Mean macronutrient intakes $( \pm S D)$ as a percent of energy for carbohydrate and protein were $63 \% \pm 5$ and $14 \% \pm 3 \%$, respectively, which is within the recommended range. When expressed as gm/kg day, carbohydrate and protein intakes were slightly lower than the 6 to $10 \mathrm{gm} / \mathrm{kg}$ recommendation for carbohydrate and $1.5 \mathrm{gm} / \mathrm{kg}$ recommendation for protein suggested by the American and Canadian Dietetic associations (12). Fat intake was $23 \% \pm 5 \%(0.92 \pm 0.37 \mathrm{gm} / \mathrm{kg})$, which is within the $<30 \%$ 
recommendation for athletes (12). The estimated average daily energy expenditure was less than what has been found in previous studies, which was expected because the swimmers were in a taper phase of training.

Table 1. Dietary intake and energy expenditure in female swimmers $(n=15)$ during taper phase

\begin{tabular}{|c|c|c|c|c|}
\hline Energy and macronutrient intake & Mean $\pm S D$ & Range & $\mathrm{kcal} / \mathrm{kg} / \mathrm{d}$ & \% kcal \\
\hline Energy intake $(\mathrm{kcal} / \mathrm{d})$ & $2,275 \pm 665$ & $1,194-3,078$ & $34 \pm 11$ & \\
\hline Protein $(\mathrm{gm})$ & $80 \pm 25$ & $46-139$ & $1.2 \pm 0.4$ & $14 \pm 3$ \\
\hline Carbohydrate (gm) & $362 \pm 109$ & $184-502$ & $5.6 \pm 1.9$ & $63 \pm 5$ \\
\hline Fat $(\mathrm{gm})$ & $60 \pm 24$ & $23-101$ & & $23 \pm 5$ \\
\hline Energy expenditure & Mean \pm SD & & & \\
\hline Sedentary Energy Expenditure $(\mathrm{kcal} / \mathrm{d})^{\mathrm{b}}$ & $1,800 \pm 87$ & & & \\
\hline Activity Related Energy Expenditure (kcal/d) & $723 \pm 132$ & & & \\
\hline Total Daily Energy Expenditure (kcal) & $2,342 \pm 158$ & & & \\
\hline Vitamin Intake & Mean \pm SD & Range & RDA & \\
\hline Vitamin A (RE) & $1,069 \pm 437$ & $50-1,833$ & $800 c$ & \\
\hline Thiamin (mg) Range RDAd & $1.9 \pm .89$ & $0.85-4.34$ & $1.1^{\mathrm{d}}$ & \\
\hline Riboflavin (mg) Range RDA ${ }^{d}$ & $2.2 \pm .68$ & $8.17-33.83$ & 14 & \\
\hline Niacin (mg) Range RDAd & $19.97 \pm 8.40$ & $8.17-33.83$ & 14 & \\
\hline Folate (mg) Range RDA ${ }^{d}$ & $309 \pm 179$ & $117.00-824.00$ & 400 & \\
\hline Vitamin C (mg) Range RDAc & $178.9 \pm 131.6$ & $49.96-516.30$ & 60 & \\
\hline \multicolumn{5}{|l|}{ Mineral intake } \\
\hline Iron (mg) & $18.5 \pm 9.3$ & & & \\
\hline Range & $6.10-40.10$ & & & \\
\hline $\mathrm{RDA}^{\mathrm{c}}$ & 15 & & & \\
\hline Calcium (mg) & $1,246.6 \pm 387.0$ & & & \\
\hline Range & $811.90-2,112.00$ & & & \\
\hline Adequate Intake ${ }^{e}$ & 1,000 & & & \\
\hline
\end{tabular}

${ }^{a} \mathrm{SD}=$ Standard deviation.

${ }^{\text {b }}$ Sedentary energy expenditure (SEE) estimated using equations 3 and 5 according to Webb et al (11) includes the energy costs of resting metabolic rate, sleeping metabolic rate, and thermogenic effect of food, and light activity.

${ }^{c}$ Does not include nutrients for which Dietary Reference Intakes have recently been established.

${ }^{d}$ Includes nutrients for which Dietary Reference Intakes have been established.

${ }^{\text {e }}$ Nutrients for which Dietary Reference Intakes are available, but an RDA has not been established.

This is the first study to look at the nutrient intake and energy expenditure of women swimmers specifically during a taper phase of training (swimming an average of 4,300 meters/day). Energy intake in this study was consistent with studies that have looked at different periods of training. Specifically, this study found estimated energy intake to be $2,275 \pm 665 \mathrm{kcal} / \mathrm{day}$, and an energy expenditure of $2,341 \pm 158 \mathrm{kcal} / \mathrm{d}$. VanHandel et al (2), who studied swimmers preparing for Olympic Trials, asked participants to complete 3-day diet records and found similar energy intakes of 2,300 $\pm 840 \mathrm{kcal} /$ day that were below optimal levels of caloric consumption because of the heavier training volume that was estimated to be approximately 3,000 kcal/day for workouts. Hawley and Williams (1) found a similar discrepancy in female swimmers with daily energy intakes and expenditures at 2,130 and 2,886 kcal/day, respectively with subjects swimming an average of 6,000 meters/day. Trappe et al (13), however, found that during very high volume training (5 to 6 hours/day, swimming 16,000-2 0,000 meters/day) energy intake was higher ( $3,136 \mathrm{kcal} /$ day) with energy expenditure at 5,593 kcal/day, and Berning et al (14) reported higher intakes (3,577 kcal/day) with energy expenditure estimated at 4,025 kcal/day 
in 14- to 18-year-old female swimmers at a national development training camp. Thus, even with these higher intakes, both studies reported a negative energy balance as was the case in the study.

Large energy deficits are often reported in female athletes during heavy training, and although underreporting is certainly an issue, other factors also may be involved, such as the effects of exercise on energy intake. Several studies have examined the relationship between physical activity and energy intake, but the exact relationship is still largely unknown. King et al (15) found that a high "dose" of exercise did not increase hunger or energy intake within 48 hours, but their study did not find any correlation between exercise-induced energy expenditure and energy intake in the short term. In support of this finding, King et al suggested that "food intake was being held in place by environmental contingencies and short-term pre-absorptive physiological responses arising from eating itself." Imbeault et al (4) found similar results in their research. They investigated the impact of the acute effects of exercise intensity at a standardized energy cost on energy intake and feeding behavior. Their results indicated no significant change in post-exercise subjective levels of hunger and fullness or in total energy and macro-nutrient intakes. In a longer study, Almeras et al (5) found that female swimmers did not alter their energy intake when training was followed by a 2-month rest period. This lack of training without a corresponding reduction in energy intake resulted in a $4 \%$ increase in body fat. These studies suggest that alterations in training for athletes are not necessarily matched with changes in dietary habits.

We also looked at the intakes of vitamins and minerals consumed by the swimmers. Because athletes generally have increased energy intake, micronutrients are usually consumed in excess of the RDA. However, our study shows that intakes of vitamin $\mathrm{E}$, pantothenic acid, biotin, iron, zinc, and copper were near the RDA.

A subsidiary focus of the study was to look at the use of reduced-fat and fat-free food products in women swimmers (Table 2). All swimmers used reduced-fat food products on a daily basis. Swimmers living off campus $(n=10)$ tended to consume an average of 3.7 servings daily of reduced-fat food products, whereas those swimmers living in residence halls $(n=5)$ consumed an average of 1.6 servings daily. This suggests in a free-living environment, swimmers are choosing more reduced-fat food products vs those swimmers living under more restricted conditions. In general, these results and those of other more recent studies have shown carbohydrate intake to be much higher (57\% to $66 \%$ of energy) in female athletes (7), (8), (9) than earlier studies (1), and that shift may be due to the increased availability of reduced-fat food products.

Table 2. Number of servings of food items, specifically labeled reduced fat, low fat, or fat free, consumed daily by female swimmers $(n=15)$ during taper phase

\begin{tabular}{|c|c|}
\hline Food category & No. servings ${ }^{\mathrm{a}}($ mean $\pm S D b)$ \\
\hline Dairy $^{c}$ & $3.8 \pm 2.9$ \\
\hline Meat & $2.0 \pm 0.8$ \\
\hline Breads/cereals & $2.3 \pm 1.3$ \\
\hline Fruits & $0.3 \pm 0.5$ \\
\hline Vegetables & $1.0 \pm 0.0$ \\
\hline Other $^{d}$ & $1.8 \pm 1.0$ \\
\hline
\end{tabular}

${ }^{a}$ Serving sizes as listed in the Food Guide Pyramid.

${ }^{c}$ Includes reduced-fat milk (ie skim, $1 \%$, and $2 \%$ fat).

"Other foods are items found in the "other" category of the Food Guide Pyramid (ie low-fat potato chips, diet soda, etc)

\section{Applications}

Most studies of dietary intake during heavy training in female athletes suggest that energy intake is inadequate, even if underreporting is considered (1), (2). Alternatively, when athletes stop training, habitual energy intake may remain too high (5). This suggests that energy intake is not tightly coupled with a change in training 
intensity. Levels of athletic training and thus energy requirements can vary dramatically depending on the competitive season (values were 4,300-19,900 meters/day between taper and peak training distance in these subjects). It is, therefore, important for the dietetic practitioner working with athletes to become familiar with training schedules, which can change rather dramatically depending on the competitive season. To avoid overor under-nutrition, athletes need to be educated that dietary intake must change to meet changing energy and macronutrient requirements.

\section{References}

(1) J.A Hawley, M.M Williams. Dietary intakes of age-group swimmers. Br J Sports Med., 25 (3) (1991), pp. $154-$ 158

(2) P.J VanHandel, K.A Cells, P.W Bradley, J.P Troup. Nutritional status of elite swimmers. J Swimming Research., 1 (1) (1984), pp. 27-31

(3) N.A King, A Tremblay, J.E Blundell. Effects of exercise on appetite control: implications for energy balance. Med Sci Sports Exerc., 29 (8) (1997), pp. 1076-1089

(4) P Imbeault, S Saint-Pierre, N Almeras, A Tremblay. Acute effects of exercise on energy intake and feeding behaviour. Br J Nutr., 77 (1997), pp. 511-521

(5) N Alméras, S Lemieux, C Bouchard, A Tremblay. Fat gajin in female swimmers. Physiol. Behav., 61 (6) (1997), pp. 811-817

(6) J.A Houmard, R Anderson Johns. Effects of taper on swim performance. Sports Med., 17 (4) (1994), pp. 224232

(7) S.S Jonnalagadda, D Bernadot, M Nelson. Energy and nutrient intakes of the United States National Women's Artistic Gymnastics Team. Int J Sport Nutr., 8 (3) (1998), pp. 230-240

(8) J.A Tanaka, H Tanaka, W Landis. An assessment of carbohydrate intake in collegiate distance runners. Int J Sport Nutr., 5 (1995), pp. 206-214

(9) K Sugiura, I Suzuki, K Kobayashi. Nutritional intake of elite Japanese track-and-field athletes. Int J Sport Nutr., 9 (2) (1999), pp. 202-212

(10) B.E Ainsworth, W.L Haskell, A.S Leon, D.R Jacobs Jr, H.J Montoye, J.F Sallis, R.S Paffenbarger Jr. Compendium of physical activities: classification of energy costs of human physical activities. Med Sci Sports Exerc., 25 (1) (1993), pp. 71-80

(11) P Webb, S Sangal. Sedentary daily expenditure: a base for estimating individual energy requirements. Am J Clin Nutr., 53 (1991), pp. 606-611

(12) Position of the American Dietetic Association and the Canadian Dietetic Association: Nutrition for physical fitness and athletic performance for adults. J Am Diet Assoc. 1993;93:691-696.

(13) T.A Trappe, A Gastaldelli, A.C Jozsi, J.P Troup, R.R Wolfe. Energy expenditure of swimmers during high volume training. Med Sci Sports Exerc., 29 (7) (1997), pp. 950-954

(14) J.R Berning, J.P Troup, P.J VanHandel, J Daniels, N Daniels. The nutritional habits of young adolescent swimmers. Int J Sport Nutr., 1 (1991), pp. 240-248

(15) N.A King, A Lluch, R.J Stubbs, J.E Blundell. High dose exercise does not increase hunger or energy intake in free living males. Eur J Clin Nutr., 51 (1997), pp. 478-483 